\title{
Twentieth-Century Trends in the Annual Cycle of Temperature across the Northern Hemisphere ${ }^{0}$
}

\author{
RICHARD C. CORNES \\ Royal Netherlands Meteorological Institute (KNMI), De Bilt, Netherlands, and Climatic Research Unit, \\ University of East Anglia, Norwich, United Kingdom
}

PHILIP D. JONES

Climatic Research Unit, University of East Anglia, Norwich, United Kingdom, and Center of Excellence for Climate Change Research, and Department of Meteorology, King Abdulaziz University, Jeddah, Saudi Arabia

\section{CHENG QIAN}

Key Laboratory of Regional Climate-Environment for Temperate East Asia, Institute of Atmospheric Physics, Chinese Academy of Sciences, and University of Chinese Academy of Sciences, Beijing, China

(Manuscript received 15 April 2016, in final form 21 March 2017)

\begin{abstract}
The annual cycle of surface air temperature is examined across Northern Hemisphere land areas (north of $25^{\circ} \mathrm{N}$ ) by comparing the results from the Climatic Research Unit Time Series (CRU TS) dataset against four reanalysis datasets: two versions of the NOAA Twentieth Century Reanalysis (20CR and 20CRC) and two versions of the ECMWF Twentieth Century Reanalysis, version 2 (ERA-20C) and version 2c (ERA-20CM). The modulated annual cycle is adaptively derived from an ensemble empirical mode decomposition (EEMD) filter, and is used to define the phase and amplitude of the annual cycle. The EEMD method does not impose a simple sinusoidal shape of the annual cycle. None of the reanalysis simulations assimilates surface temperature or land-use data. However, they differ in the parameters that are included: both ERA-20C and 20CR assimilate surface pressure data; ERA-20C also includes surface wind data over the oceans; and ERA-20CM does not assimilate any of these synoptic data. It is demonstrated that synoptic variability is critical for explaining the trends and variability of the annual cycle of surface temperature across the Northern Hemisphere. The CMIP5 forcings alone are insufficient to explain the observed trends and decadal-scale variability, particularly with respect to the decline in the amplitude of the annual cycle throughout the twentieth century. The variability in the annual cycle during the latter half of the twentieth century was unusual in the context of the twentieth century, and was most likely related to large-scale atmospheric variability, although uncertainty in the results is greatest before about 1930 .
\end{abstract}

\section{Introduction}

The annual cycle accounts for potentially $>90 \%$ of the variance of surface air temperature (SAT) measured on daily to monthly time scales across extratropical regions (Dwyer et al. 2012; Qian and Zhang 2015) and provides a fundamental control on many biophysical processes (Wallace and Osborn 2002). Across the Northern

Supplemental information related to this paper is available at the Journals Online website: http://dx.doi.org/10.1175/ JCLI-D-16-0315.s1.

Corresponding author: Richard Cornes, cornes@knmi.nl
Hemisphere, phenological data (Menzel et al. 2006) and temperature measurements (Qian et al. 2009) have indicated significant trends in the annual cycle over the course of the twentieth century, with a decreasing trend in the amplitude (Stine et al. 2009; Stine and Huybers 2012; Qian and Zhang 2015) and a tendency toward earlier phasing (Stine et al. 2009; Stine and Huybers 2012) observed over the last 50 years across most mid- to-highlatitude land areas. Yet despite the significant changes that have occurred in the annual cycle of SAT over recent decades, the subject remains underresearched when compared to the large number of studies that have examined trends in surface temperature anomalies. As a result the factors influencing the trends in the annual 
cycle across the Northern Hemisphere remain uncertain, particularly at the regional scale (Qian and Zhang 2015).

The atmospheric circulation plays a critical role in both the interannual variability and long-term trends of the annual cycle of SAT (Stine and Huybers 2012), with land-ocean coupling via advection determining the spatial structure of the annual cycle (McKinnon et al. 2013). A number of studies have examined the relationship between the annual cycle and the leading modes of atmospheric circulation variability across the Northern Hemisphere (McCabe et al. 2012; Ault et al. 2011; Stine et al. 2009; Stine and Huybers 2012). Most of these studies have aimed to determine the relative proportion of the trends in the annual cycle that can be attributed to a given mode of atmospheric circulation variability, most commonly the leading mode of variability in the Northern Hemisphere, the northern annular mode (NAM). As an example, Ault et al. (2011) investigated the influence of the northern annular and Pacific-North America (PNA) modes on phase changes across western North America, and found that while around half of the interannual variance of spring onset could be explained by the NAM and PNA, only a third of the trend over the period 1950-2005 could be explained by these modes of atmospheric circulation variability. In contrast, Stine and Huybers (2012) — expanding on the earlier analysis of Stine et al. (2009)_indicated that the trend to earlier phasing witnessed across many Northern Hemisphere land areas was largely a response of the combined effect of the NAM and PNA.

Other studies have emphasized the link between anthropogenic forcings and the changes in the annual cycle of SAT observed over the last 50 years (Mann and Park 1996; Wallace and Osborn 2002; Qian and Zhang 2015) or projected into the twenty-first century (Dwyer et al. 2012). To assess the relative importance of natural versus anthropogenic factors, several attribution studies have been conducted using model simulations (Braganza et al. 2004b; Drost and Karoly 2012; Qian and Zhang 2015). Such studies have been limited until fairly recently by uncertainty regarding the degree to which the models can replicate the observed trends. Deficiencies have been reported in the Hadley Centre Coupled Model, version 2 (HadCM2), simulations (Wallace and Osborn 2002) and also in the range of models produced under phase 3 of the Coupled Model Intercomparison Project (CMIP3; Stine et al. 2009). More recent work by Qian and Zhang (2015) has indicated that the latest CMIP models (CMIP5) perform reasonably well in simulating the observed changes in the amplitude of the annual cycle and, the authors were able to detect an anthropogenic effect on the amplitude of the annual cycle across most areas of the Northern Hemisphere. In that study greenhouse gas forcing was shown to be connected to the long-term downward trend in the amplitude of the annual cycle since 1950, whereas aerosol forcing was related to a nonlinear response, possibly in connection to the global dimming/brightening phenomenon (Wild 2009). However, in general the separation of aerosol forcing from atmospheric circulation variability is confounded by a broadly common trend throughout the latter decades of the twentieth century across the Northern Hemisphere in the aerosol-induced dimming and brightening effects and the North Atlantic Oscillation (NAO) and NAM (Chiacchio and Wild 2010; Chiacchio et al. 2011). Furthermore, as pointed out by Qian and Zhang (2015), the signal-to-noise ratio in the amplitude of the annual cycle is much lower than is typically found in trends of mean temperature as a result of the same sign of signals in the winter and summer seasons. This makes the detection and attribution of external forcing mechanisms much more difficult than in comparable studies of mean seasonal temperature.

The majority of studies that have analyzed trends in the annual cycle of SAT have focused on the latter half of the twentieth century because of the greater availability of station data over that period, and because most reanalysis simulations are only available for that period. Nonetheless, several studies have examined the annual cycle by using long instrumental data series (Thomson 1995; Stine et al. 2009), which have allowed examination of the phase and amplitude of the annual cycle over the greater part of the last 300 years. There is a need, however, to examine long-term trends in the annual cycle over a wider spatial area than is permitted by individual station series.

In this paper, we examine trends in the annual cycle across Northern Hemisphere land areas by comparing the results from four reanalysis datasets [ECMWF Twentieth Century Re-Analysis (ERA-20C) and the model only version (ERA-20CM), and two versions of the NOAA Twentieth Century Reanalysis (20CR and 20CRC)] against a purely observed dataset [Climatic Research Unit Time Series (CRU TS)]. To distinguish between the two categories of data used in this analysis we refer to CRU TS as "data" and the reanalyses as "simulations." The aims of this paper are twofold: to examine trends in the phase and amplitude of the annual cycle over the last 100 years across the Northern Hemisphere, and to investigate the relative importance of causal mechanisms on the annual cycle over that time period. We evaluate trends in the annual cycle at both the hemispheric (section 3) and gridbox scales (section 4). As described in the following section (section 2) none of the reanalysis datasets used in this study assimilates any land-based temperature data or land-use information, but they differ in the additional forcings that are included, as well as the modeling frameworks that are 
TABLE 1. A summary of the components of the reanalysis simulations used in this study. An asterisk indicates that these parameters are assimilated at the annual resolution. In the sea ice and sea surface temperature rows, the numbers following HadISST (1.1 or 2.1.0.0) indicate the version. In the sea ice row, SODAsi.2 represents the Simple Ocean Data Assimilation with sparse input, version 2. In the sea surface temperature row, COBE-SST2.2 represents the Centennial In Situ Observation-Based Estimates of Sea Surface Temperature, version 2.2. In the land observations row, the numbers following ISPD $(2.2,3.2 .9$, and 3.2.6) indicate the version. Finally, in the marine observations row, the numbers following ICOADS (2.5 and 2.5.1) indicate the version.

\begin{tabular}{|c|c|c|c|c|}
\hline & $20 \mathrm{CR}$ & 20CRC & ERA-20C & ERA-20CM \\
\hline \multicolumn{5}{|l|}{ Dataset attributes } \\
\hline Grid resolution & $2^{\circ} \times 2^{\circ}$ & $2^{\circ} \times 2^{\circ}$ & $1.125^{\circ}(\mathrm{T} 159)$ & $1.125^{\circ}(\mathrm{T} 159)$ \\
\hline Vertical levels & 28 & 28 & 91 & 91 \\
\hline Ensemble members & 56 & 56 & 10 & 10 \\
\hline Modeling environment & NCEP CFS v2 & NCEP CFS v2 & IFS Cy38r1 & IFS Cy38r1 \\
\hline \multicolumn{5}{|l|}{ Forcings } \\
\hline Aerosol & - & - & CMIP5 & CMIP5 \\
\hline $\mathrm{CO}_{2}$ & NCEP* & NCEP* & CMIP5 & CMIP5 \\
\hline Sea ice & HadISST1.1 & SODAsi.2 & HadISST2.1.0.0 & HadISST2.1.0.0 \\
\hline Sea surface temperature & HadISST1.1 & COBE-SST2.2 & HadISST2.1.0.0 & HadISST2.1.0.0 \\
\hline Solar forcing & NCEP* & NCEP* & CMIP5 & CMIP5 \\
\hline Volcanic forcing & NCEP* & NCEP* & CMIP5 & CMIP5 \\
\hline Land observations & ISPD 2.2 & ISPD 3.2 .9 & ISPD 3.2 .6 & - \\
\hline Marine observations & ICOADS 2.5 & ICOADS 2.5 & ICOADS 2.5.1 & - \\
\hline
\end{tabular}

employed. Through the comparison of these simulations against CRU TS, which implicitly contains all forcings, an estimate can be made of the relative influence on the annual cycle of forcings excluded from the reanalyses. The comparison of NOAA-20CR against observed temperature data in this way has previously been used to examine the relative importance of different forcings on trends in land-based mean temperature. Parker (2011) demonstrated that $80 \%$ of global temperature trends were on average attributable to global forcings and variations in atmospheric circulation, with the remainder being tentatively ascribed to forcings such as changes in land use, urbanization, and aerosols that were not included in the reanalysis data. Similar results were presented in Compo et al. (2013), although in contrast to Parker (2011) — who stressed the marked seasonal and regional differences between the datasets-the study by Compo et al. (2013) emphasized the general spatial covariance in trends in NOAA-20CR compared to the CRU Air Temperature Anomalies, version 3 (CRUTEM3), a purely observationbased temperature dataset.

\section{Data and methods}

\section{a. Datasets used}

Monthly means of 2-m temperature were obtained from NOAA-20CR, NOAA-20CRC (version 2, henceforth 20CR and 20CRC, respectively; Compo et al. 2011), ERA-20C, and ERA-20CM (Hersbach et al. 2015; Poli et al. 2016). These monthly means are taken to be representative of surface temperature values and are derived from 3-hourly reanalysis values. 20CR [which uses the NCEP Climate Forecast System, version 2 (NCEP CFS v2), modeling framework; see Table 1] does not assimilate any direct aerosol forcings or certain minor greenhouse gases, whereas ERA-20C (under the IFS, version Cy38r1, modeling framework) includes these forcings. Both of these datasets assimilate surface pressure data, but only ERA-20C incorporates surface wind data across ocean areas. ERA-20CM contains the same CMIP5 forcings as ERA-20C and uses the same modeling framework but does not include any synoptic pressure data or oceanic wind data. ERA-20C and ERA-20CM use the same general reanalysis approach and CMIP5 forcings, except that the latter does not assimilate any mean sea level pressure (MSLP) or marine wind data. The ECMWF and NOAA simulations consist of 10 and 56 ensemble members, respectively. Each of the 10 ensemble members of the ECMWF reanalyses is forced with a different realization of SST derived from the Hadley Centre Sea Ice and Sea Surface Temperature dataset, version 2 (HadISST2), and the ensemble captures the uncertainty in the observed data sources (Hersbach et al. 2015). 20CR and 20CRC differ in the sea ice, sea surface temperature, and surface pressure data that are used, although in the case of the latter this is only a version change of the International Surface Pressure Databank (ISPD; Cram et al. 2015).

All of the datasets used in this study-including the CRU TS, version 3.23, data (Harris et al. 2014), which were used for comparison purposes-were regridded to a common $2^{\circ} \times 2^{\circ}$ regular latitude-longitude grid using bilinear interpolation from their respective native grid formats (see Table 1) prior to any further calculations. The 
$2^{\circ} \times 2^{\circ}$ grid was chosen to match the 20CR simulationthe coarsest resolution of all datasets used in this study.

Previous analyses of the annual cycle of temperature have used the CRUTEM dataset (Jones et al. 2012) exclusively. Since CRUTEM provides anomaly values, a gridded climatology dataset invariably needs to be added to the anomalies to produce absolute temperature values in order to analyze the annual cycle. In the case of the CRU TS dataset used in this paper, absolute temperature values are provided, so these can be used to directly extract the annual cycle. This dataset also has the advantage of being available on a finer spatial resolution than the $5^{\circ} \times 5^{\circ}$ resolution of CRUTEM, with the $2^{\circ} \times 2^{\circ}$ regridded resolution of CRU TS providing a much larger sample of gridbox values with which to conduct the trend tests in this paper. To eliminate grid cells in CRU TS that are filled using climatological values, we removed any $2^{\circ} \times 2^{\circ}$ grid cells that did not contain 16 half-degree component grid cells formed from station-interpolated values. Years with fewer than 12 complete months were removed, and all years over the 1901-2010 period were required for a grid box to be used in the analysis. The station-interpolated values are calculated as part of the CRU TS gridding method and a station value is defined as a value that occurs within the decorrelation length of $1200 \mathrm{~km}$ of the target grid cell (Harris et al. 2014).

In the comparison of the reanalysis simulations against the CRU TS data it should be noted that differences between the data and simulations may arise as a result of differences in the methods used to construct the uniform grids: statistical triangulation in the case of CRU TS and dynamical modeling in the case of the reanalysis simulations. Such differences are most likely to be apparent in the regions of data sparsity where data beyond the grid cell, but within the correlation distance decay (CDD) of $1200 \mathrm{~km}$, are used. This equally applies to the reanalysis simulations, except that in this case the observations are used to drive the numerical simulation.

\section{b. Defining the amplitude and phase of the annual cycle}

In this paper we use the modulated annual cycle (MAC; $\mathrm{Wu}$ et al. 2008) as an estimate of the annual cycle of surface air temperature. The MAC, which is a 1-yr period band component without intra-annual, interannual, or longer time-scale variability, was extracted from the SAT data at each grid box using ensemble empirical mode decomposition (EEMD; Wu and Huang 2009). This was applied to the gridded datasets over the period common for all data of 1901-2010. The EEMD technique has been used in several studies to isolate the annual cycle from temperature data at both the daily (Qian et al. 2010, 2011a) and monthly time scales (Wu et al. 2008; Qian and
Zhang 2015). This annual cycle is obtained adaptively from the data without assuming a sinusoidal form of the annual cycle, which has frequently been the case in previous studies (Thomson 1995; Mann and Park 1996; Stine et al. 2009; Stine and Huybers 2012; McKinnon et al. 2013). Details of obtaining the MAC are provided in the appendix. Although the MAC was initially calculated over the period 1901-2010, spurious values may occur in the first and the last year of time series decomposed using the EEMD technique, due to the influence of end effects. These two years were removed from the MAC time series, which left the remaining 1902-2009 period for use in this analysis. Following Qian et al. (2011a) we calculate values of the instantaneous amplitude modulation by fitting a cubic smoothing spline to the local maxima of $\sqrt{(\mathrm{MAC})^{2}}$, where MAC is a monthly time series that is almost symmetric relative to the zero line. Annual averages of these smoothed monthly values complete the calculation of the amplitude of the annual SAT cycle $A$. In this way we quantify the annual amplitude as is commonly adopted in previous studies (Qian et al. 2011a; Qian and Zhang 2015). The phase of the annual cycle $\varphi$ was calculated by linearly interpolating between the monthly values of the MAC, and defining the phase as the date of the zero crossing from the start of the year, following Qian et al. (2011b). This phase metric is quite different from the sinusoid phase that has been used in several other studies (Stine et al. 2009; Stine and Huybers 2012) and marks the timing during the year at which the annual cycle passes from the cold to the warm season.

While the focus in this paper is on $A$ and $\varphi$ calculated using the EEMD technique, we also use a simple index (si) of the amplitude of the annual cycle $A_{\mathrm{si}}$, which is highly correlated with $A$. Following the example of Qian and Zhang (2015), we calculate $A_{\mathrm{si}}=\bar{x}_{\mathrm{djf}, t}-\bar{x}_{\mathrm{jja}, t}$, where $\bar{x}_{\mathrm{dj} f, t}$ is the average December-February temperature with $t$ denoting the year dated by the January-February months, and $\bar{x}_{\mathrm{jia}, t}$ being the average June-August temperature. The $A_{\mathrm{si}}$ has previously been used by Jones et al. (2003) to examine amplitude changes in long SAT series across Europe. In Fig. 1 we show the MAC, $A, A_{\mathrm{si}}$, and $\varphi$ components, along with the associated monthly mean temperature time series, for one arbitrarily chosen grid square. The annual average of the smoothed envelope values $(A)$ are compared against the corresponding $A_{\mathrm{si}}$ values (Fig. 1b), from which it can be seen that the two measures are highly correlated $(r=0.8)$ on the interannual basis as well as on longer time scales, which corresponds to similar findings by Qian and Zhang (2015). However, while $A_{\mathrm{si}}$ has the advantage of being much easier to calculate than $A$ and is a useful check on the results from the EEMD method, the results from the index will also contain weather-induced singularities and 

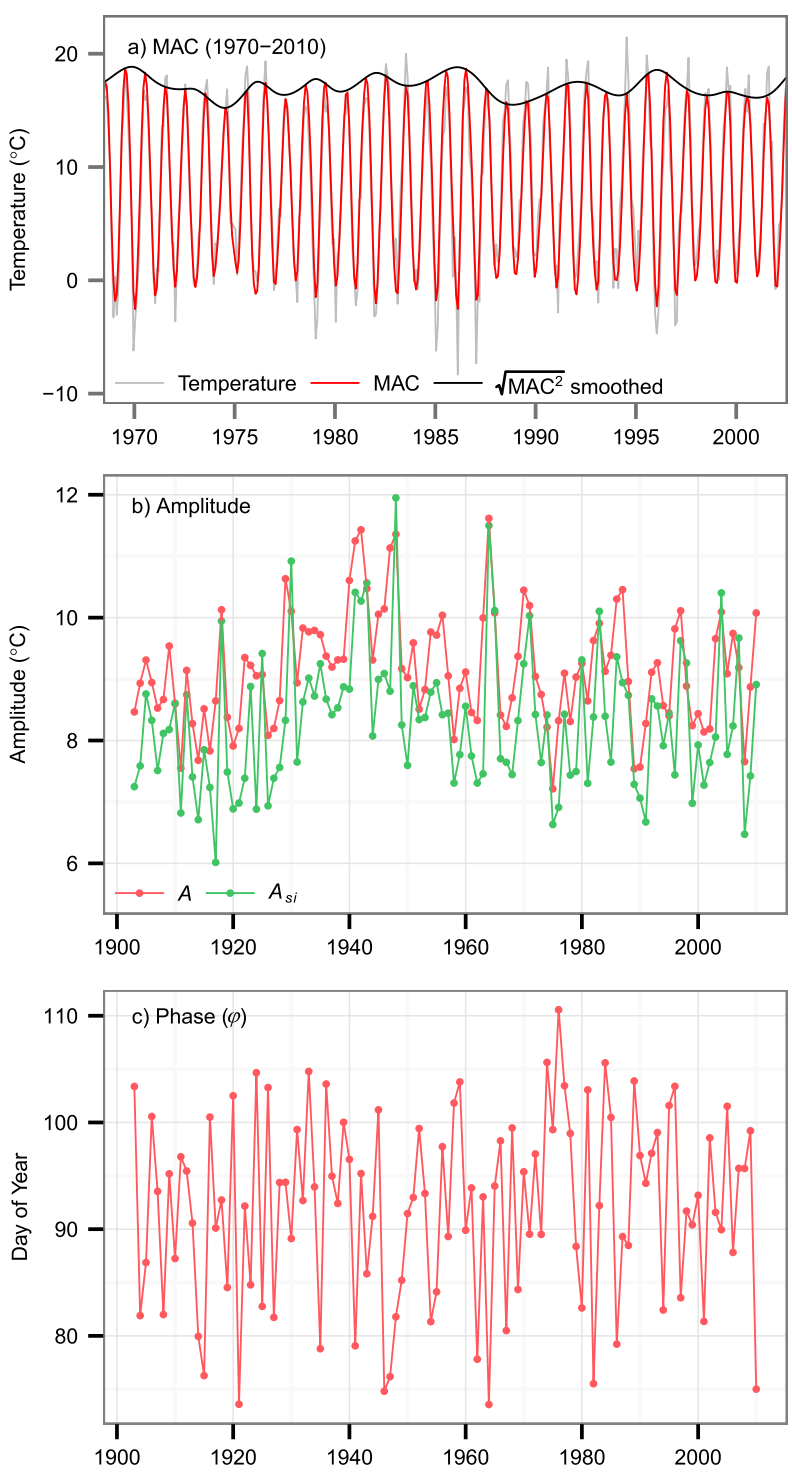

FIG. 1. The components of the annual cycle of SAT used in this study, demonstrated for one grid box $\left(51^{\circ} \mathrm{N}, 11^{\circ} \mathrm{E}\right.$; central-eastern Germany) calculated from the CRU TS data. (a) The EEMDderived annual cycle is shown against the SAT data, along with the envelope of the MAC for the 1970-2009 period. (b) The amplitude of the annual cycle as calculated from the annual averages of the MAC envelope, alongside the simple index (i.e., $A_{\mathrm{si}}$ ). (c) Plot of the phase. Note the different time scales used in (b) and (c) compared to (a).

harmonics that are beyond our definition of the annual cycle as the amplitude-frequency modulated annual cycle (Wu et al. 2008). Furthermore, in the early part of the series (before 1930 ) there is much greater uncertainty in the series particularly in data-sparse regions and during the summer, which results in a much greater interannual variance in the $A_{\mathrm{si}}$ in these regions. Outliers in the data have a large effect on the seasonal means, which significantly influences the $A_{\mathrm{si}}$, although this does not seem to leverage such a significant effect when $A$ is derived using the EEMD method. These effects are not apparent in Fig. 1, however, because those data come from a region with high-quality observations through the time series.

\section{Hemispheric-scale trends}

\section{a. Trends in the amplitude}

Average annual anomalies of $A$ across the Northern Hemisphere from the reanalysis simulations and CRU TS data were examined by calculating anomalies at each grid box relative to the 1950-2000 average; these values were then area weighted averaged across the Northern Hemisphere using the cosine of latitude. In these calculations the reanalysis simulations are the averages across the 10 and 56 ensemble members for the NOAA and ECMWF reanalyses, respectively. The trend in hemispheric-averaged $A$ is broadly consistent throughout the twentieth century between CRU TS and the reanalysis datasets, with the exception of ERA-20CM (Fig. 2). Over the 1950-2009 period these results correspond to the findings of other studies (Qian and Zhang 2015), which show a downward trend in the Northern Hemispheric average over the latter half of the twentieth century. However, the results in Fig. 2 also indicate a pronounced decadal-scale variability throughout the twentieth century and a strong nonlinear trend over the 1970-2009 period, which was preceded by relative stability in the early decades of the twentieth century. The standardized cumulative anomalies in Fig. 2 were calculated for each of the $N$ time series values by summing all values from the first value to $N$, following Mächel et al. (1998). This cumulative anomaly is a form of low-pass filter, although contrary to more usual smoothing functions, sustained rising (falling) values indicate the predominance of positive (negative) anomaly values; turning points indicate a transition from periods dominated by either positive or negative anomalies and in this way the filter highlights changepoints in a time series. In Fig. 2 the points of inflection for the datasets excluding ERA-20CM typically occur around the late 1970s, when a shift to more negative anomalies occurs. There is also an indication of a tendency to more positive anomalies since the 1990s, which is most prominent in the 20CR and 20CRC simulations compared to either the CRU TS data or ERA-20C simulation.

The time series of ERA-20CM in Fig. 2 is markedly different from the other series, both in terms of the interannual/decadal variability and the long-term trend. A suppressed interannual variability is apparent in that series and the trend throughout the twentieth century is generally linear. As ERA-20CM contains only CMIP5 radiative forcings, sea surface 
a) ERA Reanalyses

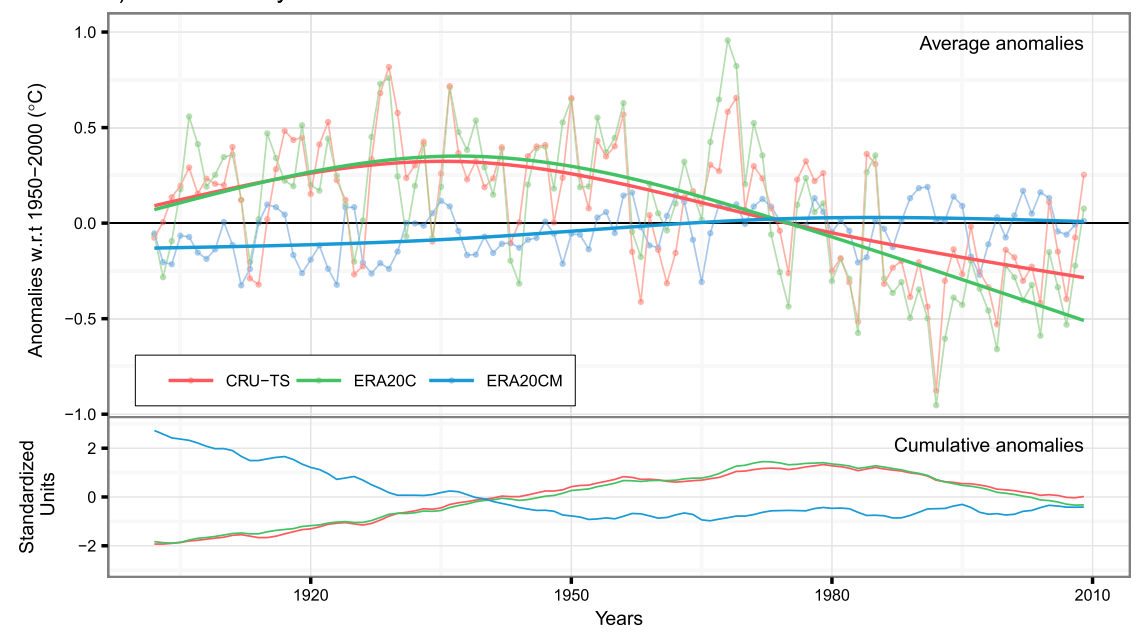

b) $20 C R$ Reanalyses

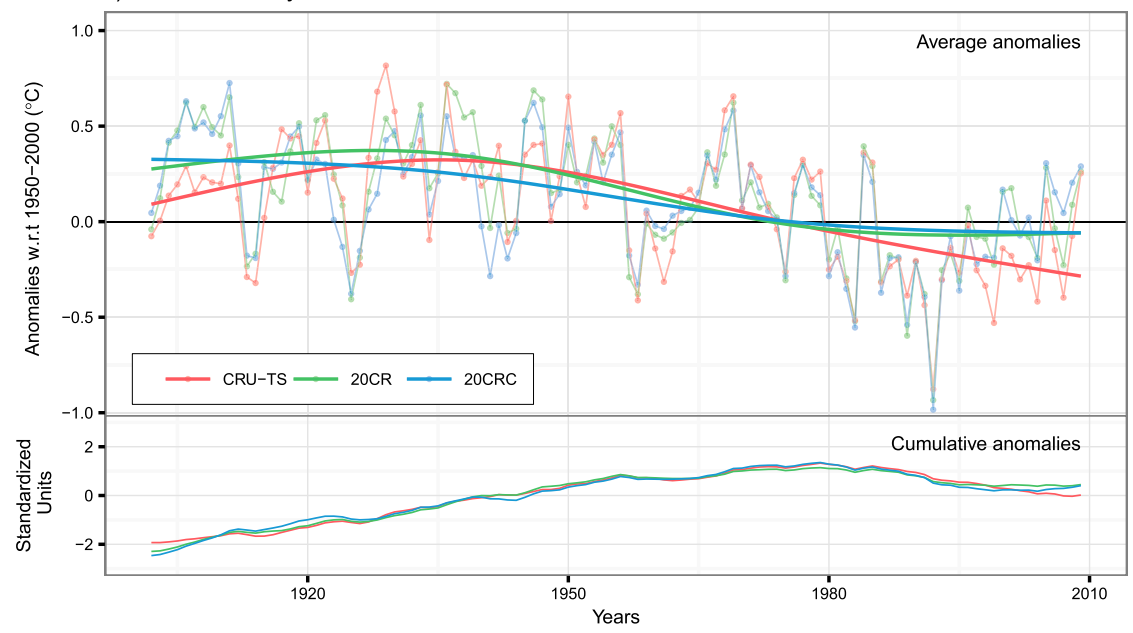

FIG. 2. Average anomalies across the Northern Hemisphere of the amplitude of the annual cycle derived from the (a) ERA-20C and ERA-20CM or (b) 20CR and 20CRC simulations and CRU TS data. In (a), a cubic smoothing spline value, which highlights the low-frequency variability, is included. In each panel the CRU TS results (red) are replicated. The cumulative anomalies are calculated from the hemispheric average anomalies as the sum from 1 to $N$ for each of $N$ time steps; these values have then been standardized using $Z$ scores. For similar results from $A_{\mathrm{si}}$ see Fig. S1 in the supplemental information.

temperature, and sea ice values (see Table 1), the results shown in Fig. 2 suggest that at the hemispheric scale the trends and variability in $A$ that are evident in the other reanalysis simulations and CRU TS data are profoundly affected over the course of the twentieth century by the synoptic variability that is common to both the ERA-20C and 20CR/20CRC simulations, and not just the forcings contained in ERA-20CM. This follows the reasoning of Parker (2011) in his examination of trends in mean surface temperature using the CRUTEM3 data and 20CR simulation, and relies on the assumption that all modes of variability and forcings would be expected to be demonstrated in the CRU TS data.

To test the robustness of the trends in $A$ across the ERA-20CM and 20CRC ensembles, we have calculated the median and range (10th-90th percentiles) of hemispheric-mean $A$ anomalies across the ensemble members of these simulations: the values are calculated across 56 members in the case of 20CRC and 10 members in ERA-20CM. The uncertainty range in surface temperature in ERA-20CM on a global mean basis is largely a function of the internal variability of the model as triggered by SST forcings. For each ensemble 


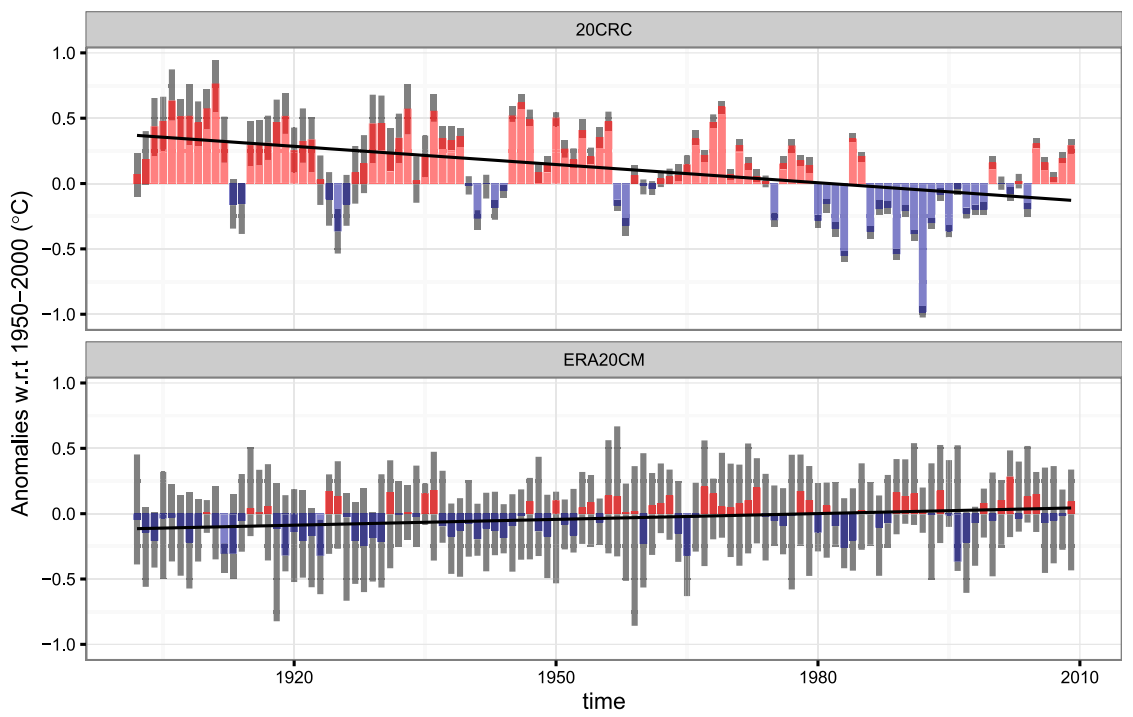

FIG. 3. Northern Hemisphere averages of the amplitude of the annual cycle calculated across each of the ensemble members. The shading indicates the yearly 10th and 90th percentiles across the ensemble members, and the colored bars indicate the median of these values. The trend line is derived using a generalized additive mixed model applied to the median values expressed as a function of time. For similar results from $A_{\mathrm{si}}$ see Fig. S2.

member a different SST distribution is used and while the spread in the SST ensemble decreases significantly over the course of the twentieth century, this is not apparent in the ERA-20CM simulation, suggesting that SST acts as initialization for the low-frequency atmospheric variability (Hersbach et al. 2015). In contrast, the spread across 20CRC ensemble members changes markedly over time, indicating direct conditioning of the atmospheric variability through the assimilated barometric pressure observations (Compo et al. 2011). As a reflection of this, the amplitude of the annual cycle across the ERA-20CM ensemble members displays a consistent spread in values throughout the time series compared to 20CRC (Fig. 3). This indicates that the observed trend in ERA-20CM toward positive amplitude values arises from a consistent model response to the input forcings, rather than from a variation of input data, notably the variation in SST data over time. A much higher interannual variability is evident in 20CRC, which further illustrates the importance of synoptic pressure variability on year-to-year and longer time-scale variability. While the interannual variability generally exceeds the uncertainty range on a year-to-year basis after $\sim 1930$, there is a larger uncertainty range in the 1900-30 period, which can be attributed to the much lower observed data input during that period (Compo et al. 2011). This is also likely to be the case in the ERA-20C simulation, which similarly used the barometric pressure data from the ISPD. While the ISPD version used in these two datasets differs, there has been no significant increase in data quantity across the Northern Hemisphere in the newer version of ISPD used in ERA-20C compared to the older version used in 20CRC.

In Fig. 3 we have included the trend in the median across the ensemble of $A$ values. This trend was calculated using a generalized additive mixed model (GAMM; Wood 2006), where the dependent variable (hemispheric anomalies) is expressed as a smooth function of time. The smoothing parameter of the cubic splines is chosen using generalized cross validation (GCV). Autocorrelation up to lag 4 is significant in the 20CRC values and has been taken into account in the GAMM. Temporal autocorrelation in the ERA-20CM time series was less than for 20CRC (significant up to lag 2), which further reflects the constraining of the numerical model through the assimilation of MSLP observations in 20CRC. The penalty in the GAMM was set to 10; this limits the effective degrees of freedom (EDF) of the model although it must be noted that the actual value of the EDF is chosen by GCV (Wood 2006). Through the use of the GAMM, we do not make an a priori assumption about the linearity of the trend in these time series. Nonetheless, the smoothing spline produced using this method is linear $(\mathrm{EDF}=1)$ for both the ERA-20CM and 20CRC ensemble median time series. All of the ensemble members in ERA-20CM show a similar positive trend throughout the twentieth century (Fig. S4), although the magnitude varies across the members. Similarly, a negative trend is apparent in all of the ensemble members of 20CRC (Fig. S3). These results add further support to the assertion that direct synoptic 
a) ERA Reanalyses

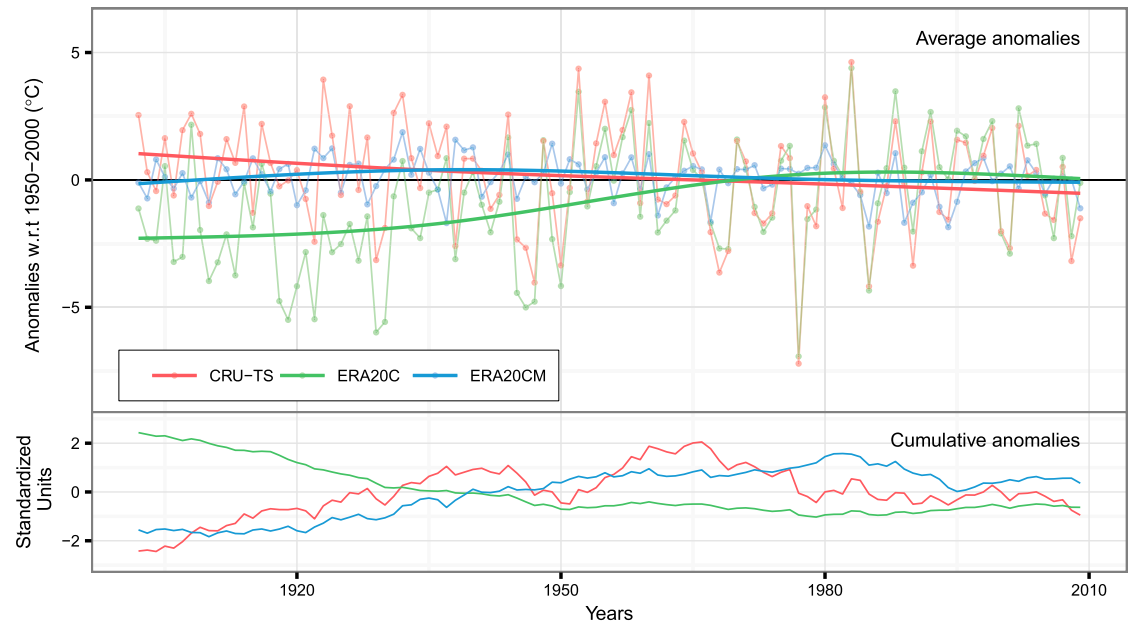

b) $20 \mathrm{CR}$ Reanalyses

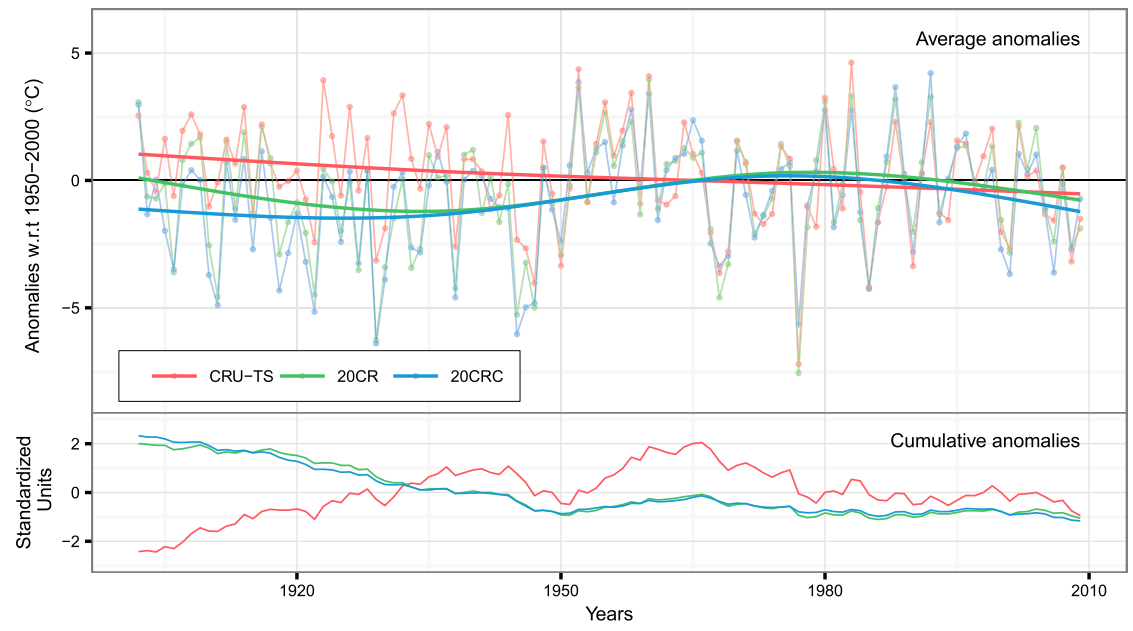

FIG. 4. As in Fig. 2, but for the phase of the annual cycle.

variability is largely responsible for the tendency toward lower values and the pronounced decadal-scale variability apparent in the amplitude of the annual cycle across Northern Hemisphere land areas over the course of the twentieth century.

\section{b. Trends in the phase}

The hemispheric average anomalies for the phase of the annual cycle (Fig. 4) indicate much less consistency across the datasets in terms of the low-frequency variability and long-term trends than is the case for the amplitude of the annual cycle. ERA-20C, 20CR, and 20CRC show some correspondence in terms of generally negative anomalies during the first half of the twentieth century and anomalies that oscillate across the zero line throughout the latter half of the century, but this contrasts with the results from CRU TS where there is no such temporal variation. In comparison to the results from ERA-20CM, the interannual variation is much more consistent across CRU TS, ERA-20C, 20CR, and 20CRC than is the case with the lower-frequency variations.

As with $A$ the spread across the trends in $\varphi$ (Fig. 5) from the 20CRC simulation is much greater before $\sim 1930$, but is generally consistent in the ERA-20CM simulation over the time period. Nonetheless the increasing trend and decadal-scale fluctuation in the 20CRC results are in stark contrast to the lack of trend in the ERA-20CM results. This feature is also apparent when considering the results for each of the ensemble members (Figs. S5 and S6).

\section{Gridpoint trends}

In this section we investigate regional-scale variations in $A$ and $\varphi$ by examining gridpoint trends calculated 


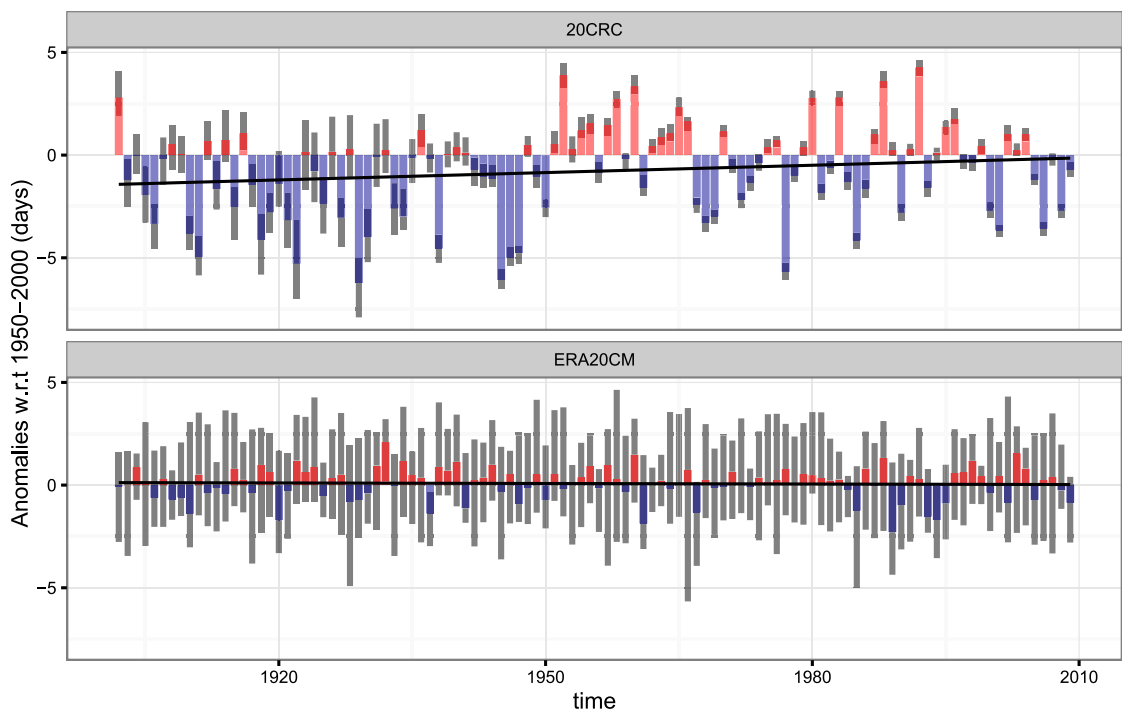

FIG. 5. As in Fig. 3, but for the phase of the annual cycle.

from the reanalysis simulations and CRU TS data. We have calculated the trends over three nonoverlapping time periods (1902-50, 1951-80, and 1981-2009). As indicated in the previous section, the reliability of the 20CR, 20CRC, and ERA-20C simulations is likely to be worse in the earlier decades of the twentieth century on account of the much sparser data coverage compared to later periods. By separating the time series into three periods, an assessment can be made of this reliability. The 1951 date is a reasonable cut off since the values in 20CR and 20CRC are generally less reliable before 1952 (Compo et al. 2011), although as seen above this is particularly the case before $\sim 1930$. Furthermore, the splitting of the time series into three time periods allows us to better capture the nonlinear trend that is apparent in the hemispheric averages of Fig. 2, especially in the CRU TS data and ERA-20C/20CR simulations. Although it should not be expected that all grid cells will show the same nonlinear trend as the hemispheric average, the separation of the trend analysis into these three periods also allows us to compare the results against studies that have identified an aerosol-induced influence on the annual cycle, which has been linked to the global dimming/ brightening phenomenon. Dimming is generally ascribed to the period between the 1950s and 1980s, with brightening occurring thereafter, although the exact timing and magnitude of the two phases is spatially variable (Wild 2009). Associated with the dimming/brightening phenomenon is the downward trend in the diurnal temperature range that has been observed over the latter half of the twentieth century (Braganza et al. 2004a).

The trends in this section were calculated using the Thiel-Sen method, with confidence intervals estimated using the prewhitening technique described by Zhang et al. (2000) and refined by Wang and Swail (2001). This allows us to take into account lag- 1 autocorrelation in the significance testing of the trends. Trends in the difference series (reanalysis minus CRU TS) of $A$ and $\varphi$ were also calculated. By taking the differences between respective time series, variance common to both datasets is removed and this allows for a stricter quantification of the difference in trends between the data, which are highly correlated on the interannual and longer time scales [see Cornes and Jones (2013) and references therein].

\section{a. Trends in the amplitude}

The average value of the trends in $A$ across the Northern Hemisphere (Table 2) indicate generally weak trends over the 1902-50 and 1951-80 periods, although in the latter period the trends are negative. In the case of ERA$20 \mathrm{C}$ the average trend over 1951-80 is more than double the rate observed in the other datasets. Average trends in $A$ over the 1981-2009 period are positive but the value varies considerably depending on the dataset considered: trends in the 20CR/20CRC simulations are much greater than in the CRU TS data and ERA-20C/ERA-20CM simulations.

Gridpoint trends in most of the datasets indicate distinct regional differences beyond the average values (Fig. 6), although in general the results from CRU TS and the reanalysis simulations-excluding ERA-20CM-are broadly comparable in terms of the spatial pattern of trends in the three periods considered. Of significance are the reversal of trends in $A$ across Europe from strongly negative trends in the period 1951-80 to positive trends in the period 1981-2009, and the large positive trends across 
TABLE 2. Averages of amplitude and phase trends across the Northern Hemisphere. Trends are expressed as rate of change per decade.

\begin{tabular}{|c|c|c|c|c|c|c|c|}
\hline Period & Dataset & $A$ & $A_{\text {diff }}$ & $A_{\mathrm{si}}$ & $A_{\text {si,diff }}$ & $\varphi$ & $\varphi_{\text {diff }}$ \\
\hline \multirow[t]{5}{*}{$1902-50$} & $20 \mathrm{CR}$ & -0.01 & -0.04 & 0.01 & -0.02 & -0.36 & 0.12 \\
\hline & 20CRC & -0.06 & -0.09 & -0.05 & -0.08 & -0.12 & 0.33 \\
\hline & ERA-20C & 0.03 & 0.00 & 0.04 & 0.00 & 0.14 & 0.57 \\
\hline & ERA-20CM & 0.01 & -0.02 & 0.00 & -0.03 & 0.17 & 0.52 \\
\hline & CRU TS & 0.03 & - & 0.04 & - & -0.36 & - \\
\hline \multirow[t]{5}{*}{$1951-80$} & 20CR & -0.09 & -0.04 & -0.02 & -0.06 & -0.82 & 0.33 \\
\hline & 20CRC & -0.09 & -0.05 & -0.03 & -0.05 & -0.74 & 0.40 \\
\hline & ERA-20C & -0.18 & -0.14 & -0.05 & -0.11 & -0.84 & 0.36 \\
\hline & ERA-20CM & -0.01 & 0.06 & 0.03 & 0.00 & 0.18 & 1.38 \\
\hline & CRU TS & -0.03 & - & 0.04 & - & -1.18 & - \\
\hline \multirow[t]{5}{*}{ 1981-2009 } & $20 \mathrm{CR}$ & 0.16 & 0.09 & 0.07 & 0.09 & -0.2 & -0.11 \\
\hline & 20CRC & 0.22 & 0.15 & 0.14 & 0.14 & -0.44 & -0.28 \\
\hline & ERA-20C & 0.00 & -0.05 & -0.08 & -0.06 & 0.05 & 0.15 \\
\hline & ERA-20CM & 0.02 & -0.06 & 0.02 & 0.03 & 0.18 & 0.31 \\
\hline & CRU TS & 0.07 & - & -0.01 & - & -0.05 & - \\
\hline
\end{tabular}

northern China and Siberia during the period 1981-2009 (Fig. 6c). In the earliest period (1902-50) the trends in $A$ show less coherence across the datasets. The 20CR and 20CRC simulations in particular show a quite different pattern over certain areas compared to CRU TS and ERA-20C, especially over central Asia where a negative trend is observed, and the north-central United States, where a positive trend occurs, which is locally much

a) Trends $1902-1950$
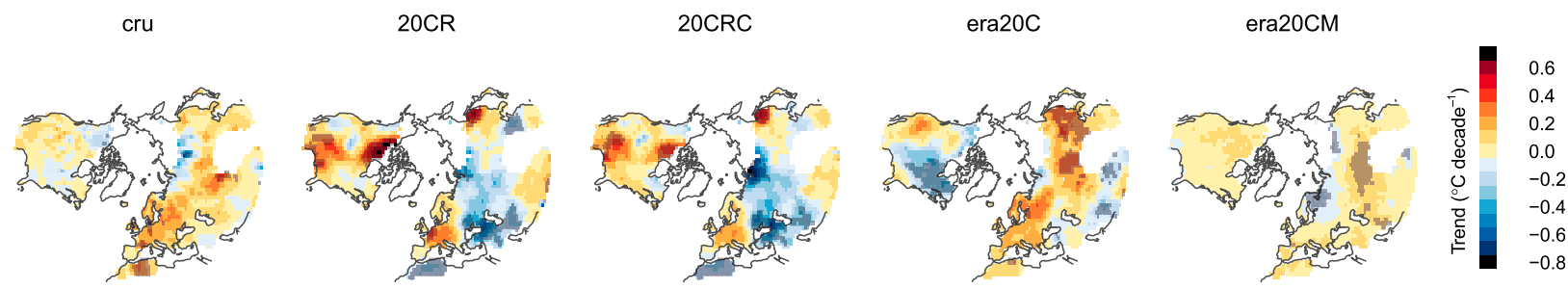

b) Trends 1951-1980
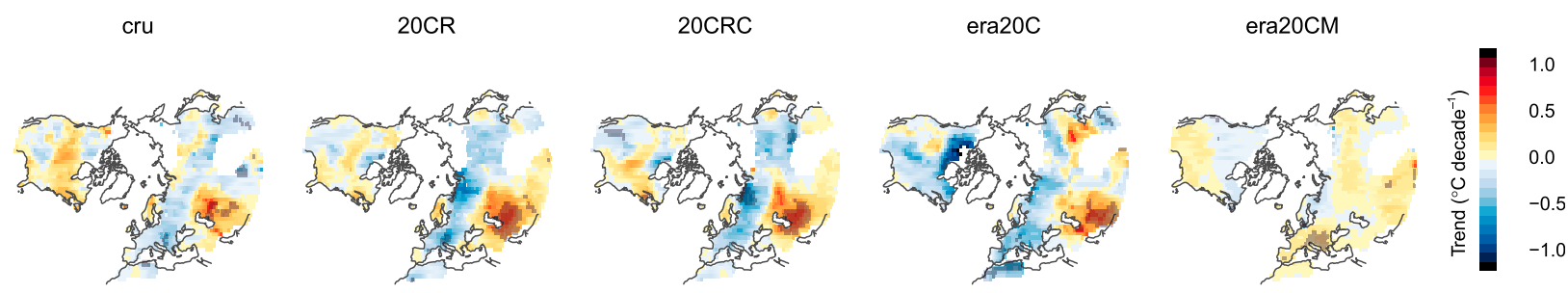

c) Trends 1981-2009

cru

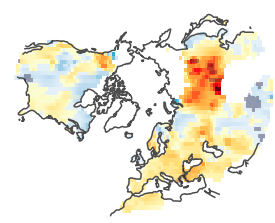

$20 \mathrm{CR}$

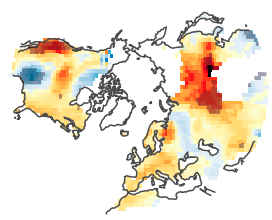

20CRC

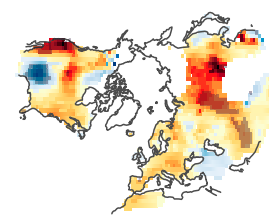

era20C

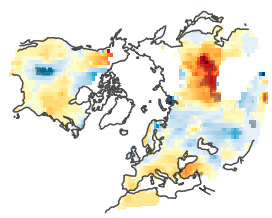

era20CM

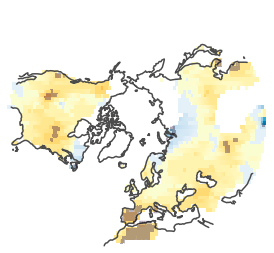

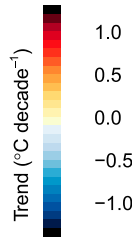

FIG. 6. Gridbox trends in the amplitude of the annual cycle calculated across three time periods. Gray shading indicates trends locally significant at $p<0.05$ (two-tailed test). Note the different scales used between the panels. 

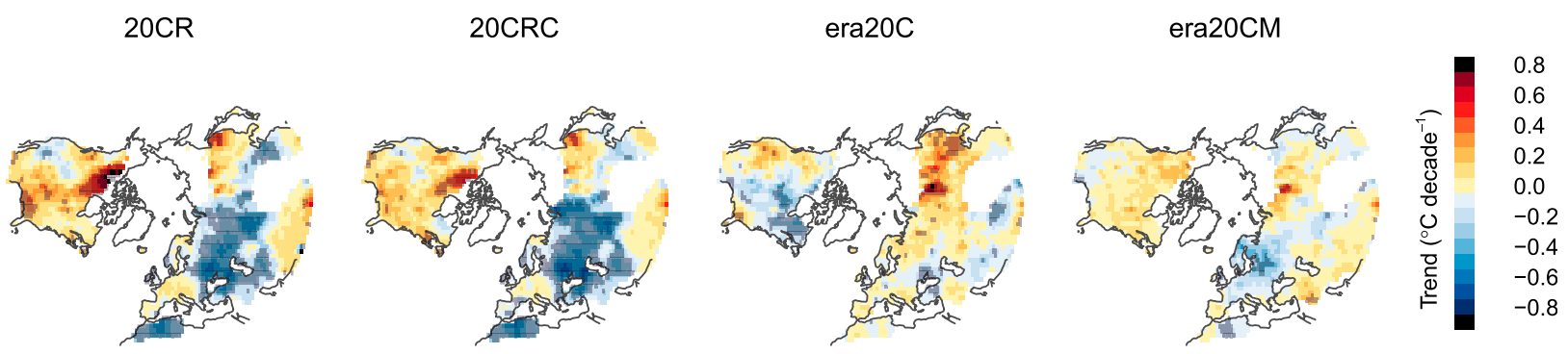

b) Trends 1951-1980
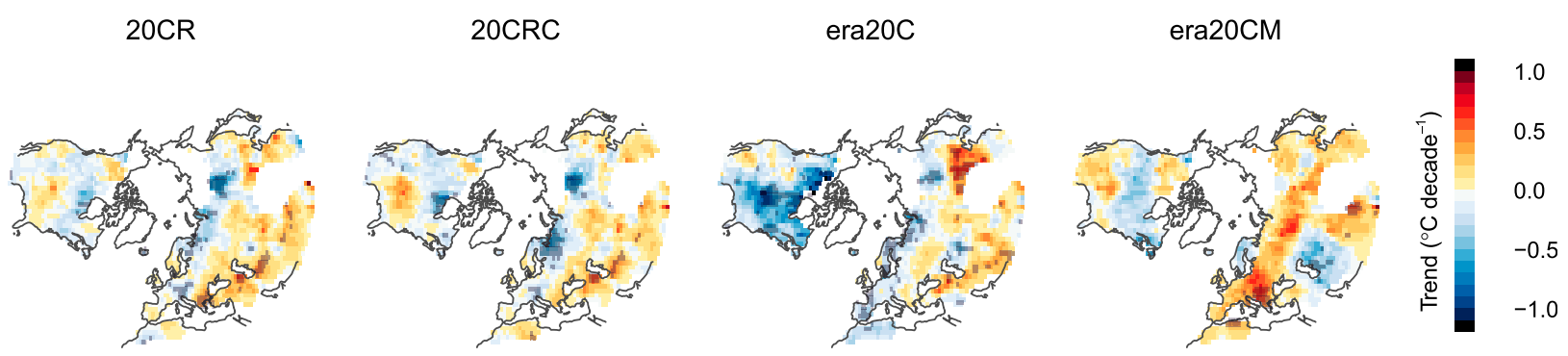

c) Trends 1981-2009

$20 \mathrm{CR}$

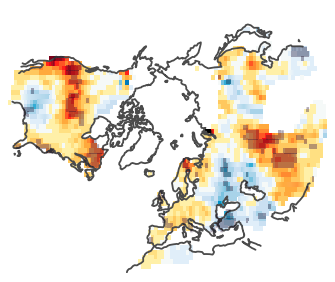

20CRC

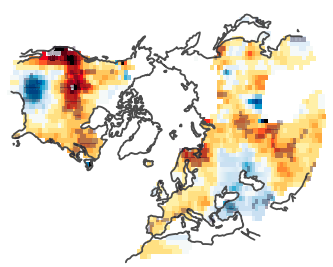

era20C

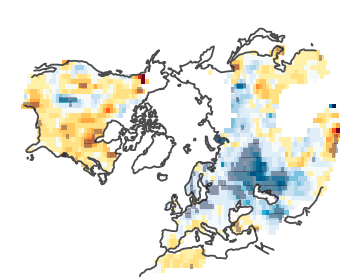

era20CM

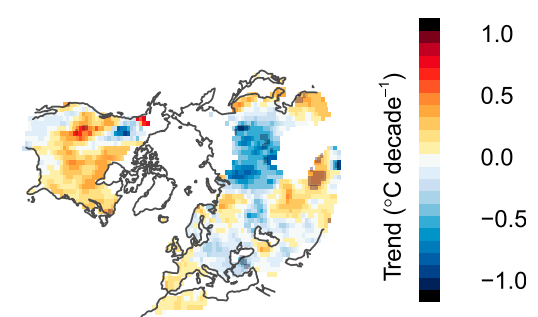

FIG. 7. As in Fig. 6, but for trends calculated from the difference series (reanalysis minus CRU TS).

stronger than in CRU TS. The trends in the difference series of $A$ (reanalysis minus CRU TS; Fig. 7a) further demonstrate these anomalous regions and show that the strong negative trend in central Asia is significantly different from the trend in CRU TS. The anomalous trends in northern Canada in the 20CR simulations (Fig. 7a) are likely attributable to the well-documented deficiencies in the sea ice data in the 20CR data during that period (Lindsay et al. 2014), which have a clear effect on trends in $A$ across northern Canada. This is largely rectified in the 20CRC dataset although anomalies relative to CRU TS are still evident in that dataset.

As with the hemispheric average trends described above, the results from ERA-20CM are quite different from the other data. With the exception of certain regions/time periods, a relatively weak positive trend is apparent in ERA-20CM across most regions and during all of the three time periods considered (Fig. 6).

Across the contiguous United States a crescentshaped pattern of trends is apparent in $A$ over the 1981-2009 period (Fig. 6c): an increase in $A$ occurs across western and north-central regions while a decrease is observed across the southeast of the continent. This pattern is evident in the results from the 20CR simulation and to a lesser extent ERA-20C, and while it can be seen in the CRU TS data, it is less clearly defined. The crescent-shaped pattern is absent in the ERA20CM simulation. Previous studies have identified a so-called warming hole in trends of surface air temperature in the southeastern United States, where trends over the 1950-99 period in the west of the country 
outpaced those in the east by a factor of 2 (Meehl et al. 2012, 2015). A cooling trend was observed in certain southeastern regions of the country, which was much greater in the winter compared to the summer, and in the context of the annual cycle of temperature would result in an increasing trend in $A$. A reversal in SAT trends, again greatest in winter, occurred around the late 1990s (Meehl et al. 2015) and it is this reducing seasonal differential that we see in the amplitude of the annual cycle. Meehl et al. (2012) concluded that the major factor influencing this feature was atmospheric circulation changes resulting from decadalscale atmosphere-ocean interactions associated with the interdecadal Pacific oscillation (IPO). The results in Fig. 6c support this view: the 20CR and ERA-20C simulations include SST data, and would be expected to provide a good representation of the IPO over this time period on account of the high density of landand ship-derived pressure data. A discrepancy exists, however, in the results from 20CR and ERA-20C in that the trend over the western United States is much weaker, and is comparable to CRU TS; the negative trends over the "warming hole" region of the southeastern United States are comparable.

To assess the uncertainty in the gridbox trends we have calculated the trends in $A$ for each member of the 56-member 20CRC ensemble, with the spread across these trends taken as a measure of the uncertainty of the results. This uncertainty does not quantify model bias but provides a measure of internal variability that results from the model when unconstrained by the observations. The greatest spread of trends occurs across northern Canada during the 1902-50 period (Fig. 8). This is likely to be related to remaining problems with the sea ice data described above, but may also arise from the poor coverage of barometric pressure data across the region during that period. Uncertainty in the trends is also quite large across parts of China, and this is consistent across the three time periods considered. Across most of the other regions the $2 \sigma$ error range in the trends is generally less than $\pm 0.1^{\circ} \mathrm{C}$ decade $^{-1}$.

\section{b. Trends in the phase}

The average trend in $\varphi$ across the Northern Hemisphere in the ERA-20CM simulation is an increase of approximately two days over the 1902-2009 period (Table 2); this rate of increase is broadly consistent across the three time periods and indicates a spring phase, that is, zero crossing of the MAC (see section 2) that has occurred later in the year. The rate of change in the other datasets and across the three time periods differs considerably. The spatial pattern of trends in $\varphi$ (Fig. 9) shows a much smoother pattern than $A$, with a more coherent spatial pattern of regional differences evident. Over the 1902-50 period, positive trends are shown in all datasets across much of the United States, indicating an increasing trend of $\sim 1.5$ days decade ${ }^{-1}$. Over the 1951-80 period a distinct region of strong positive trends is evident over Europe in all datasets apart from ERA-20CM. The trend is consistent across ERA-20C, 20CR, 20CRC, and CRU TS and is on the order of 7 days decade ${ }^{-1}$ compared with $\sim 1$ day in the case of ERA-20CM, indicating a delay in spring phase onset of around a week per decade. In contrast, over the 1981-2009 period a reversal of this pattern is evident, with earlier phasing evident at the rate of 2 days decade ${ }^{-1}$. The difference plots (Fig. 10) reinforce these assertions.

\section{Monthly trends}

The modulated annual cycle, as used in this paper, defines the annual cycle of temperature as an intrinsic component of the climate system (Wu et al. 2008). In this way we exclude "noise," which we consider to be beyond our definition of the annual cycle, and this allows us to investigate the wider changes of the annual cycle beyond the phase and amplitude metrics. For example, using a sample of long instrumental and documentary series across the Northern Hemisphere, Jones et al. (2003) have shown that the negative trend in the amplitude throughout the twentieth century is attributable to a greater warming of the winter season compared to summer. Using the MAC we are able to examine not just these changes in the CRU TS data and the reanalysis simulations, but also trends for all months of the year. To achieve this we have calculated the trends for each month of the year over the three time periods defined above from the MAC values. The trends have been averaged across six regions using all grid cells in the respective regions. The regions are defined as Canada, $50^{\circ}-70^{\circ} \mathrm{N}, 130^{\circ}-60^{\circ} \mathrm{W}$; East Asia, $25^{\circ}-50^{\circ} \mathrm{N}, 40^{\circ} \mathrm{E}-180^{\circ}$; Mediterranean, $30^{\circ}-50^{\circ} \mathrm{N}$, $60^{\circ} \mathrm{W}-40^{\circ} \mathrm{E}$; northern Asia, $50^{\circ}-70^{\circ} \mathrm{N}, 40^{\circ} \mathrm{E}-180^{\circ}$; northern Europe, $50^{\circ}-70^{\circ} \mathrm{N}, 60^{\circ} \mathrm{W}-40^{\circ} \mathrm{E}$; and the United States, $30^{\circ}-50^{\circ} \mathrm{N}, 130^{\circ}-60^{\circ} \mathrm{W}$.

In most cases in Fig. 11 the results from 20CR and 20CRC match those of CRU TS and ERA-20C closely. An exception is evident during the warm half of the year across East Asia and northern Asia throughout the periods $1951-80$ and 1981-2010. Across those two regions the trends in 20CR and 20CRC tend to be lower than the other data during 1951-80 and much higher during the 1981-2010 period.

As has been identified throughout this paper, the trends in ERA-20CM tend to be quite different from the other data considered, and the results from the 
a) Trends Spread 1902-1950

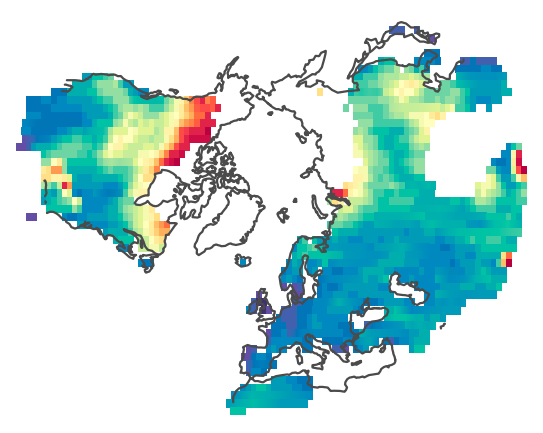

b) Trends Spread 1951-1980

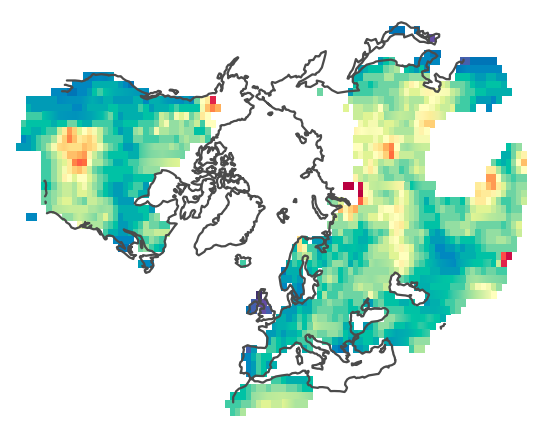

c) Trends Spread 1981-2009

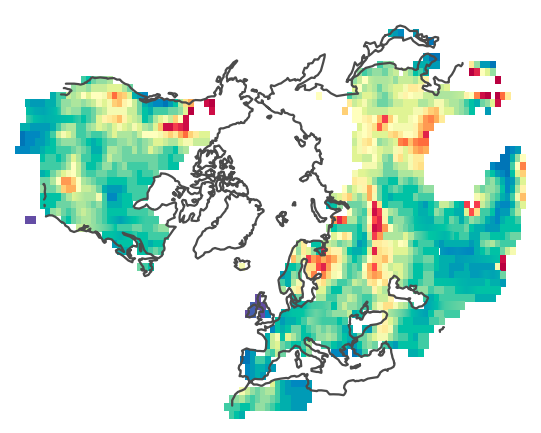

$2 \sigma$ Trend $\left({ }^{\circ} \mathrm{C}\right.$ decade $\left.^{-1}\right)$ d) Trends Spread 1902-1950

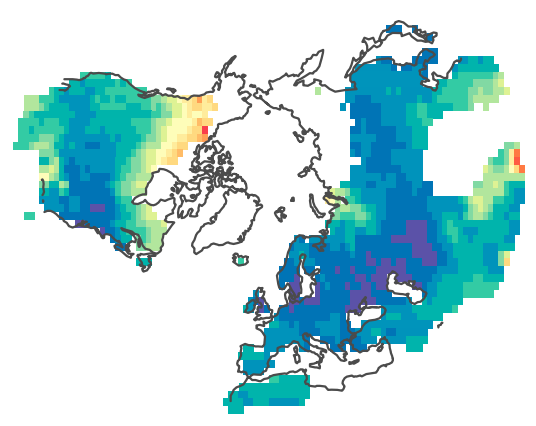

e) Trends Spread 1951-1980

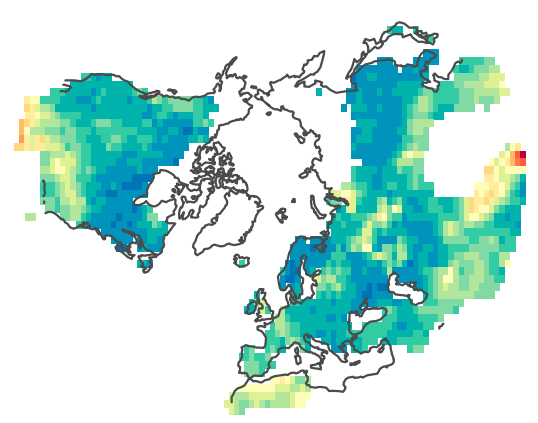

f) Trends Spread 1981-2009

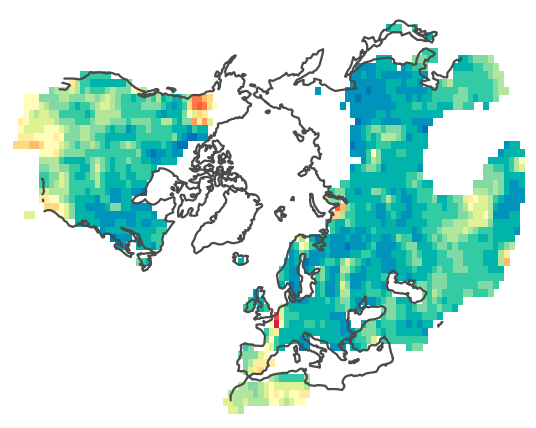

$2 \sigma$ Trend (days decade ${ }^{-1}$ )

0.0

0.5

1.0

1.5

2.0

FIG. 8. Spread of trends in (a)-(c) $A$ and (d)-(f) $\varphi$ in the $20 \mathrm{CRC}$ data. The spread is indicated by two std devs across the trends. Note the different scales used in (a)-(c) compared to (d)-(f). 
a) Trends 1902-1950
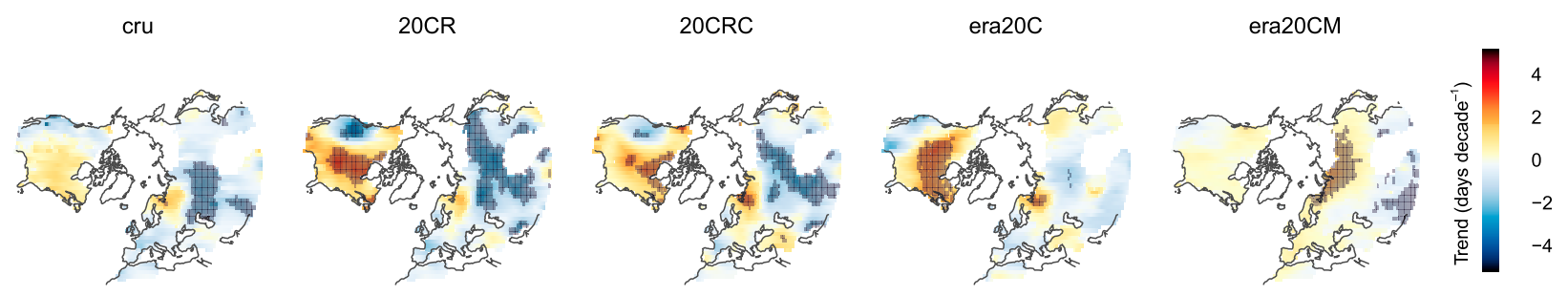

b) Trends 1951-1980
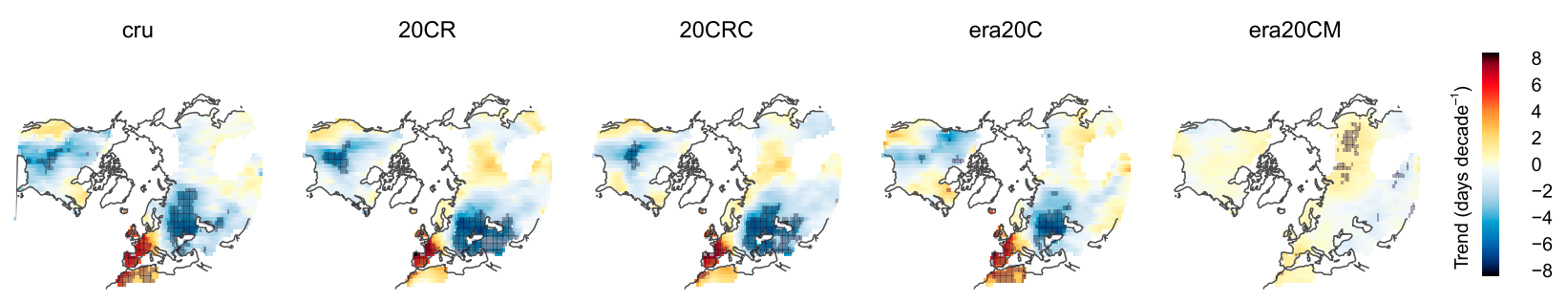

c) Trends 1981-2009
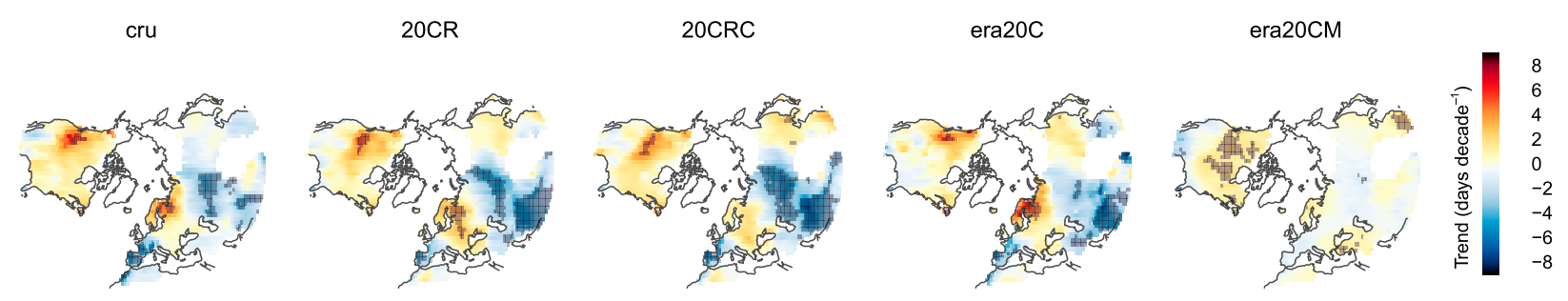

FIG. 9. As in Fig. 6, but for the phase of the annual cycle.

monthly trends in Fig. 11 are no exception. There tends to be much less month-by-month variation in the trends in ERA-20CM compared to the other datasets. During the 1901-50 period there is similarly very little variation across months in all the datasets and across the six regions. This is reflected in the weak trend in $A$ across most Northern Hemispheric land areas identified above. However, in the 1951-80 and 1981-2010 periods the anomalous monthly variation in ERA-20CM trends is clearly apparent when compared with the significant monthly variation evident in the other datasets. A notable example is northern Europe during the 1981-2010 period, when a pronounced negative trend is observed throughout the spring months (March-May) in all datasets apart from ERA-20CM. Furthermore, the spread in trends per month across ensemble members in ERA-20CM (Fig. S10) is as large as or larger than the spread across the datasets in Fig. 11. These results reinforce the message that that it is the constraining of the reanalysis data through the barometric pressure data (20CR and ERA-20C) and oceanic wind observations (ERA-20C) that is vital for the reanalysis simulations to replicate the trends and variability seen in the observed data.

\section{Discussion and conclusions}

Previous studies have demonstrated the important role that the dominant modes of atmospheric circulation play in the variability of the annual cycle across the Northern Hemisphere, notably the Pacific-North American (PNA) mode, the northern annular mode (NAM), and/or the Pacific decadal oscillation (PDO) (Ault et al. 2011; McCabe et al. 2012; Stine et al. 2009; Stine and Huybers 2012). For example, the study by Stine and Huybers (2012) identified a west-east split across Europe in the trends of both $A$ and $\varphi$, and was attributed to the influence of the NAM. In this paper we have not explicitly defined the relationship between the annual cycle and these modes of atmospheric circulation variability but rather consider the total response to the atmospheric circulation at the hemispheric and gridcell scales through the comparison of reanalysis simulations that assimilate barometric pressure and/or marine wind observations 
a) Trends $1902-1950$
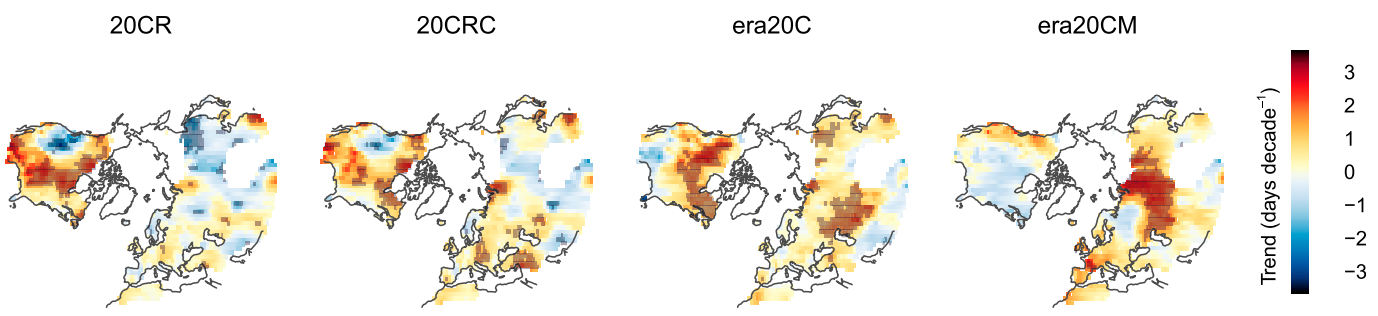

b) Trends 1951-1980
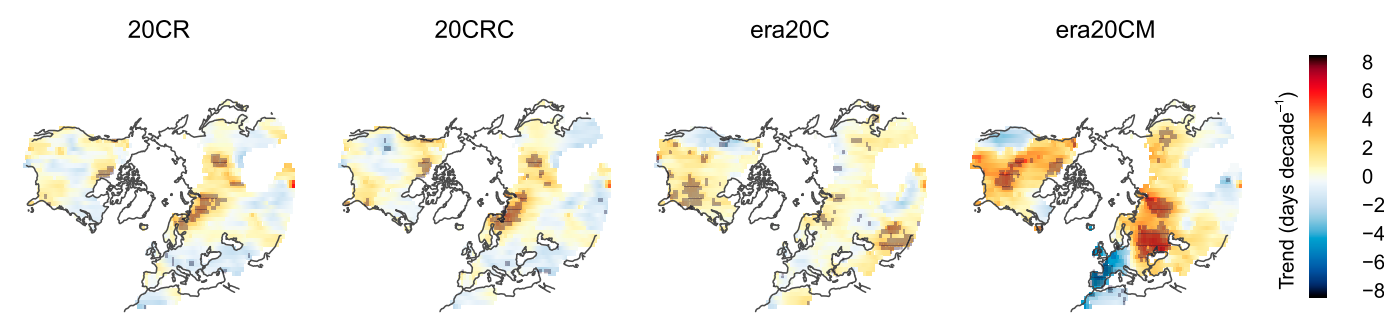

c) Trends 1981-2009
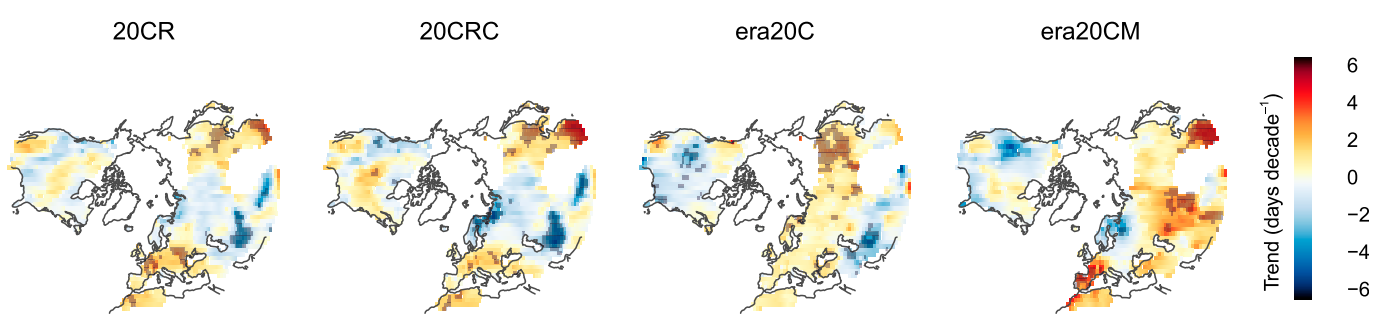

FIG. 10. As in Fig. 7, but for the phase of the annual cycle.

and sea surface temperature, in a modeling framework that includes various other forcing parameters. This approach does not dictate what the response of the annual cycle to atmospheric circulation variability should be at a given place or time but allows for a dynamic response, with the response being determined by the particular modeling scheme used in each reanalysis. Nonetheless, the spatial pattern of trends in the phase and amplitude of the annual cycle over the latter half of the twentieth century, particularly over Europe, is consistent with the annual cycle response to variability of the NAM seen, for example, in the results of Stine and Huybers (2012). Furthermore, we also see a signature of the NAM at the hemispheric scale in the time series of the amplitude of the annual cycle; the phase, being much more dominated by regional-scale variability, is less coherent at the hemispheric scale. However, while the NAM has a significant control on the variability of the annual cycle, other atmospheric circulation effects are also likely to be present in the results, which are of local or regional significance and which are included implicitly in the results-an example of this is the observed west-east split in trends across the United States over the latter half of the twentieth century in connection with the warming hole (Meehl et al. 2012). It should be stressed, however, that using this reanalysis comparison approach we are not able to separate the influence of natural internal variability from anthropogenic forcings or to evaluate the influence of land use or aerosol forcing.

In this analysis we make the assumption that the response to different forcings, and atmospheric circulation variability, is the same across the reanalyses, and also the observed data. Clearly this is a simplification since a statistical interpolation is used in the construction of the CRU TS data-with stations for a particular grid cell included if they fall within the $1200-\mathrm{km}$ distance-decay radius-while surface temperature in the reanalysis simulations is dictated by the modeling framework used. The effect of this discrepancy in the results presented in this paper is likely to be largest at the gridbox scale and in areas of poor station coverage, in either the CRU TS or reanalysis data. At the 

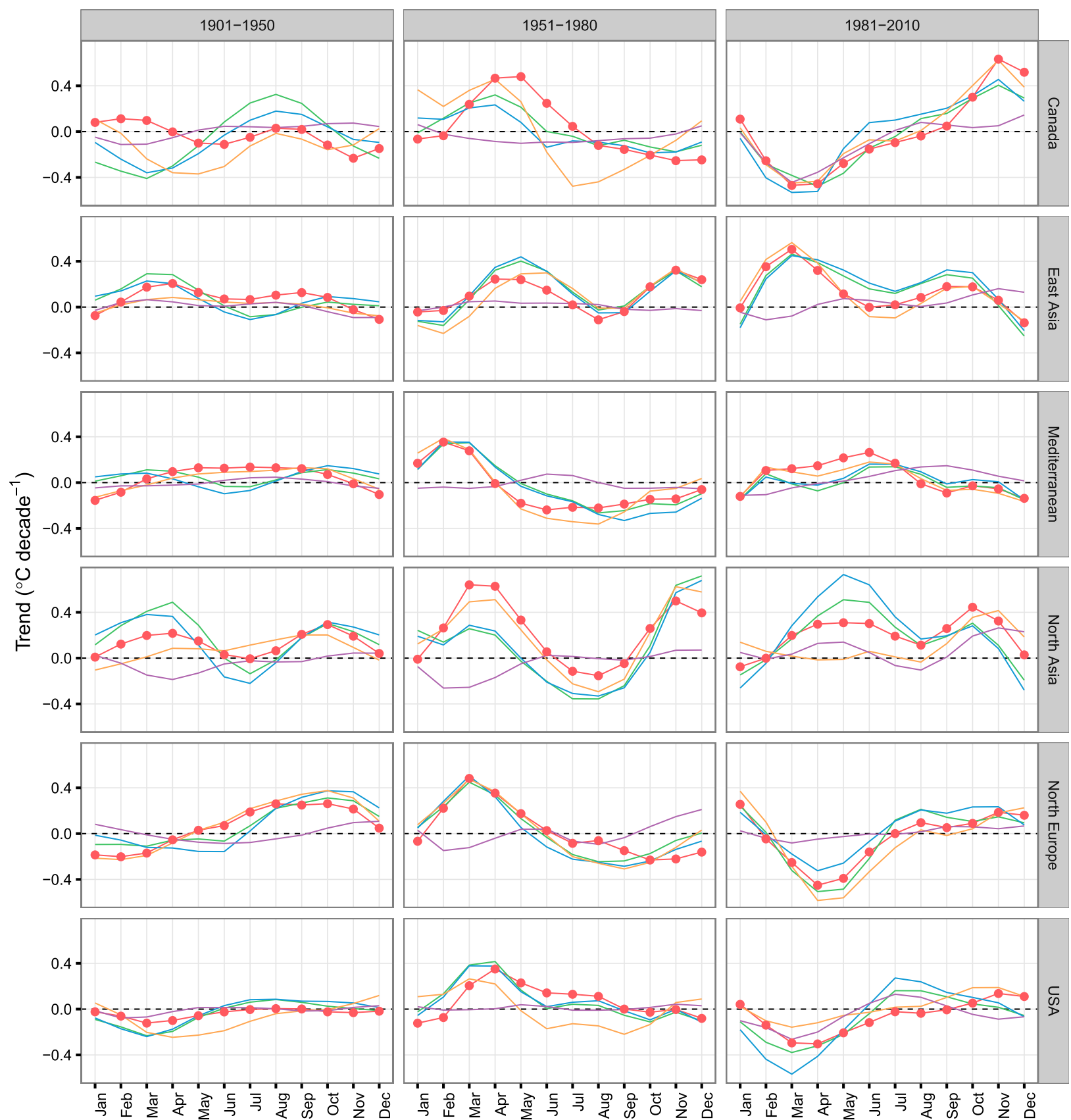

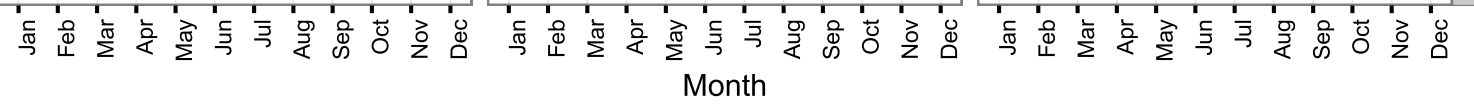

$$
\longrightarrow \text { cru } \longrightarrow \text { 20CR } \longrightarrow \text { 20CRC } \longrightarrow \text { era20C } \longrightarrow \text { era20CM }
$$

FIG. 11. Monthly trends in the EEMD-derived MAC values averaged across six regions in the CRU TS data and reanalysis simulations.

hemispheric scale any such differences are expected to be minor. In the comparison between reanalysis simulations the assumption of a constant forcing response is only valid in the comparison of ERA-20CM against ERA-20C since both datasets use the same modeling framework (IFS Cy28r1) and forcings (Hersbach et al. 2015).
Between 20CR/20CRC and ERA-20C/ERA-20CM the assumption may not hold since different modeling frameworks are used in these reanalyses. However, the generally close association between the results from 20CR/20CRC and ERA-20C suggests that any modeling difference is less important than the observed data that 
have been assimilated, and which provide a vital constraint on the reanalysis simulation.

The results from ERA-20CM in this paper can be viewed as a form of control, in the sense that the synoptic variability in that dataset is not constrained by observed MSLP and/or marine wind data as is the case with the other reanalysis simulations analyzed in this paper. When compared against the results from the simulations that contain the direct synoptic variability, as well as CRU TS which implicitly contains all forcings, we see that most of the interannual and lower-frequency variability in the amplitude of the annual cycle throughout the twentieth century arises from synoptic variability; the increasing trend attributable to the forcings contained in ERA-20CM is largely linear throughout the twentieth century with little correspondence to the synopticconstrained simulations at the interannual/decadal scale (Fig. 2). However, a complication arises in this respect since all of the reanalyses, including ERA-20CM, assimilate sea surface temperature (see Table 1). Since the SST data contain all forcings and natural variability implicitly, in a similar manner to the CRU TS data on land, a strict isolation of the CMIP5 forcings using this dataset is not possible. However, it is clear that it is only when the reanalysis simulation is constrained by synoptic MSLP and/or marine data that the reanalysis simulation approaches the purely observed data (CRU TS). This indicates that it is the advective properties of the synoptic variability that is the key to understanding changes in the annual cycle throughout the twentieth century, through ocean-atmosphere coupling, rather than the atmospheric circulation response per se. This corresponds to the findings of McKinnon et al. (2013). However, the longer time scale analyzed in this paper has enabled us to identify that the strong nonlinear trend in the amplitude of the annual cycle across the Northern Hemisphere in the latter half of the twentieth century was preceded by relative consistency back to 1902; this is also apparent in the synoptic-forced reanalyses. It should be stressed, however, that the ability of the reanalysis datasets to depict the influence of the atmospheric circulation variability is directly related to the quality and quantity of the assimilated data. Across certain areas, such as northern China, and for most regions prior to $\sim 1930$ the input data are relatively sparse, which reduces confidence in the results for these regions and periods. This relative data sparsity occurs in the assimilated MSLP data and also the SST and sea ice data.

The method used in this paper to define the annual cycle — the modulated annual cycle (Wu et al. 2008) - has allowed us to examine more detail about changes in the annual cycle than is permitted from the amplitude and phase metrics alone. This has revealed a complex change to the annual cycle throughout the twentieth century, and one that is regionally specific. However, as with the trends and variability in the amplitude and phase of the annual cycle at the hemispheric and gridcell resolutions, the reanalysis data are only able to replicate the observed changes when constrained with synoptic-scale observations, which again suggests the critical influence that atmosphere-ocean variability has on the annual cycle, although the degree to which human activity affects synoptic variability itself remains an open question.

Acknowledgments. The Twentieth Century Reanalysis data were obtained from NOAA/OAR/ESRL PSD, Boulder, Colorado, USA, from their Web site at http://www.esrl.noaa.gov/psd/; the ERA-CLIM data were obtained from ECMWF (http://www.ecmwf.int/ en/research/climate-reanalysis/era-20c); and the CRU TS data were obtained from the Centre for Environmental Data Analysis (CEDA; http://www.ceda.ac.uk/). CRU TS is currently supported by the U.K. National Centre for Atmospheric Science (NCAS). The EEMD analysis in this paper was carried out on the High Performance Computing Cluster supported by the Research and Specialist Computing Support service at the University of East Anglia. We thank the three reviewers for their comments, which helped to improve the manuscript. The contribution of Cheng Qian in this study is supported by the National Natural Science Foundation of China (Grant 41675093) and the Youth Innovation Promotion Association of the Chinese Academy of Sciences (2016075).

\section{APPENDIX}

\section{Calculation of the Modulated Annual Cycle}

In most previous analyses of the annual cycle of temperature the annual cycle has been defined using phase and amplitude metrics using an annual-period sinusoid function obtained using the complex demodulation method (Thomson 1995; Mann and Park 1996) or the Fourier transform method (Stine et al. 2009; Stine and Huybers 2012). Using these methods a symmetrical form of the annual cycle is assumed. In this paper we use the modulated annual cycle (MAC; Wu et al. 2008) obtained adaptively using an adaptive and temporally local filter [ensemble empirical mode decomposition (EEMD)] (Wu and Huang 2009), which does not assume a particular shape of the annual cycle. This considers the annual cycle as an intrinsic, nonlinear, and nonstationary component of the climate system, which is in contrast to the Fourier transform approach, which considers the annual cycle to be an extrinsic component. Using the EEMD 
approach we are able to examine changes to the annual cycle in its entirety; this allows, for example, the analysis in section 5 of the trends for each month of the year in the context of the MAC. The effectiveness of the MAC has been shown in several previous studies (e.g., Wu et al. 2008; Qian et al. 2011b; Qian and Zhang 2015).

The EEMD method is a development of empirical mode decomposition (EMD; Huang and $\mathrm{Wu}$ 2008) whereby a time series is decomposed into a finite set of oscillation components possessing various time scales [named intrinsic mode functions (IMFs)] and a longterm trend through a sifting process. A common problem with the EMD is "mode mixing," whereby a given IMF consists of very different signals. To alleviate this problem the EEMD was proposed whereby the underlying idea is to obtain the arithmetic mean of multiple observations by adding multiple white noise realizations to the target data to mimic a scenario of multiple trials of observations for a single trial of observations and carry out the EMD procedure for each trial. Through using an ensemble, EEMD cancels various realizations of which noise added to each trial of the ensemble and finally obtains scale-consistent signals. The procedure of extracting the MAC using this method follows the example of $\mathrm{Wu}$ et al. (2008). In the case of monthly data the second and third components of the EEMD result often have similar numbers of extrema that are phase locked. To obtain a relatively narrow band annual cycle, the second and third components are combined and subjected to a single EMD decomposition.

To extract the MAC in the temperature series investigated in this paper the following stages were followed: 1) White noise with an amplitude of 0.5 times the standard deviation of the monthly temperature series was added to the time series. 2) The data with added white noise were then decomposed into IMFs. 3) Steps 1 and 2 were repeated 1000 times with a new white noise series added each time. 4) The mean across the 1000 ensemble members was calculated for each of the IMFs. 5) The second and third components of the EEMD result were added. 6) This new series was subjected to a further EMD, and the first IMF of that procedure was taken as the MAC.

\section{REFERENCES}

Ault, T. R., A. K. Macalady, G. T. Pederson, J. L. Betancourt, and M. D. Schwartz, 2011: Northern Hemisphere modes of variability and the timing of spring in western North America. J. Climate, 24, 4003-4014, doi:10.1175/2011JCLI4069.1.

Braganza, K., D. J. Karoly, and J. M. Arblaster, 2004a: Diurnal temperature range as an index of global climate change during the twentieth century. Geophys. Res. Lett., 31, L13217, doi:10.1029/2004gl019998.
,-- A. C. Hirst, P. Stott, R. J. Stouffer, and S. F. B. Tett, 2004b: Simple indices of global climate variability and change. Part II: Attribution of climate change during the twentieth century. Climate Dyn., 22, 823-838, doi:10.1007/ s00382-004-0413-1.

Chiacchio, M., and M. Wild, 2010: Influence of NAO and clouds on long-term seasonal variations of surface solar radiation in Europe. J. Geophys. Res., 115, D00D22, doi:10.1029/ 2009JD012182.

— T. Ewen, M. Wild, M. Chin, and T. Diehl, 2011: Decadal variability of aerosol optical depth in Europe and its relationship to the temporal shift of the North Atlantic Oscillation in the realm of dimming and brightening. J. Geophys. Res., 116, D02108, doi:10.1029/2010JD014471.

Compo, G. P., and Coauthors, 2011: The Twentieth Century Reanalysis Project. Quart. J. Roy. Meteor. Soc., 137, 1-28, doi:10.1002/qj.776.

, P. D. Sardeshmukh, J. S. Whitaker, P. Brohan, P. D. Jones, and C. McColl, 2013: Independent confirmation of global land warming without the use of station temperatures. Geophys. Res. Lett., 40, 3170-3174, doi:10.1002/grl.50425.

Cornes, R. C., and P. D. Jones, 2013: How well does the ERAInterim reanalysis replicate trends in extremes of surface temperature across Europe? J. Geophys. Res. Atmos., 118, 10 262-10276, doi:10.1002/jgrd.50799.

Cram, T. A., and Coauthors, 2015: The International Surface Pressure Databank version 2. Geosci. Data J., 2, 31-46, doi:10.1002/ gdj3.25.

Drost, F., and D. Karoly, 2012: Evaluating global climate responses to different forcings using simple indices. Geophys. Res. Lett., 39, L16701, doi:10.1029/2012GL052667.

Dwyer, J. G., M. Biasutti, and A. H. Sobel, 2012: Projected changes in the seasonal cycle of surface temperature. J. Climate, $\mathbf{2 5}$, 6359-6374, doi:10.1175/jcli-d-11-00741.1.

Harris, I., P. D. Jones, T. J. Osborn, and D. H. Lister, 2014: Updated high-resolution grids of monthly climatic observations-The CRU TS3.10 dataset. Int. J. Climatol., 34, 623-642, doi:10.1002/ joc.3711.

Hersbach, H., C. Peubey, A. Simmons, P. Berrisford, P. Poli, and D. Dee, 2015: ERA-20CM: A twentieth-century atmospheric model ensemble. Quart. J. Roy. Meteor. Soc., 141, 2350-2375, doi:10.1002/qj.2528.

Huang, N. E., and Z. Wu, 2008: A review on Hilbert-Huang transform: Method and its applications to geophysical studies. Rev. Geophys., 46, RG2006, doi:10.1029/2007RG000228.

Jones, P. D., K. R. Briffa, and T. J. Osborn, 2003: Changes in the Northern Hemisphere annual cycle: Implications for paleoclimatology? J. Geophys. Res., 108, 4588, doi:10.1029/ 2003JD003695.

- D. H. Lister, T. J. Osborn, C. Harpham, M. Salmon, and C. P. Morice, 2012: Hemispheric and large-scale land-surface air temperature variations: An extensive revision and an update to 2010. J. Geophys. Res. Atmos., 117, D05127, doi:10.1029/ 2011JD017139.

Lindsay, R., M. Wensnahan, A. Schweiger, and J. Zhang, 2014: Evaluation of seven different atmospheric reanalysis products in the Arctic. J. Climate, 27, 2588-2606, doi:10.1175/ JCLI-D-13-00014.1.

Mächel, H., A. Kapala, and H. Flohn, 1998: Behaviour of the centres of action above the Atlantic since 1881. Part I: Characteristics of seasonal and interannual variability. Int. J. Climatol., 18,1-22, doi:10.1002/(SICI)1097-0088(199801)18:1<1:: AID-JOC225>3.0.CO;2-A. 
Mann, M. E., and J. Park, 1996: Greenhouse warming and changes in the seasonal cycle of temperature: Model versus observations. Geophys. Res. Lett., 23, 1111-1114, doi:10.1029/96GL01066.

McCabe, G. J., T. R. Ault, B. I. Cook, J. L. Betancourt, and M. D. Schwartz, 2012: Influences of the El Niño Southern Oscillation and the Pacific decadal oscillation on the timing of the North American spring. Int. J. Climatol., 32, 2301-2310, doi:10.1002/ joc.3400.

McKinnon, K. A., A. R. Stine, and P. Huybers, 2013: Spatial structure of the annual cycle in surface temperature: Amplitude, phase, and Lagrangian history. J. Climate, 26, 7852-7862, doi:10.1175/JCLI-D-13-00021.1.

Meehl, G. A., J. M. Arblaster, and G. Branstator, 2012: Mechanisms contributing to the warming hole and the consequent U.S. east-west differential of heat extremes. J. Climate, 25, 6394-6408, doi:10.1175/JCLI-D-11-00655.1.

- _ - and C. T. Y. Chung, 2015: Disappearance of the southeast U.S. "warming hole" with the late 1990s transition of the interdecadal Pacific oscillation. Geophys. Res. Lett., 42, 5564-5570, doi:10.1002/2015GL064586.

Menzel, A., and Coauthors, 2006: European phenological response to climate change matches the warming pattern. Global Change Biol., 12, 1969-1976, doi:10.1111/j.1365-2486.2006.01193.x.

Parker, D. E., 2011: Recent land surface air temperature trends assessed using the 20th Century Reanalysis. J. Geophys. Res., 116, D20125, doi:10.1029/2011jd016438.

Poli, P., and Coauthors, 2016: ERA-20c: An atmospheric reanalysis of the twentieth century. J. Climate, 29, 4083-4097, doi:10.1175/ JCLI-D-15-0556.1.

Qian, C., and X. Zhang, 2015: Human influences on changes in the temperature seasonality in mid- to high-latitude land areas. J. Climate, 28, 5908-5921, doi:10.1175/JCLI-D-14-00821.1.

— C. Fu, Z. Wu, and Z. Yan, 2009: On the secular change of spring onset at Stockholm. Geophys. Res. Lett., 36, L12706, doi:10.1029/2009GL038617.

_ Z. Wu, C. Fu, and T. Zhou, 2010: On multi-timescale variability of temperature in China in modulated annual cycle reference frame. Adv. Atmos. Sci., 27, 1169-1182, doi:10.1007/ s00376-009-9121-4.
— C. Fu, and Z. Wu, 2011a: Changes in the amplitude of the temperature annual cycle in China and their implication for climate change research. J. Climate, 24, 5292-5302, doi:10.1175/JCLI-D-11-00006.1.

— Z. Wu, C. Fu, and D. Wang, 2011b: On changing El Niño: A view from time-varying annual cycle, interannual variability, and mean state. J. Climate, 24, 6486-6500, doi:10.1175/ JCLI-D-10-05012.1.

Stine, A. R., and P. Huybers, 2012: Changes in the seasonal cycle of temperature and atmospheric circulation. J. Climate, 25, 73627380, doi:10.1175/JCLI-D-11-00470.1.

,-- , and I. Y. Fung, 2009: Changes in the phase of the annual cycle of surface temperature. Nature, 457, 435-440, doi:10.1038/nature07675.

Thomson, D. J., 1995: The seasons, global temperature, and precession. Science, 268, 59-68, doi:10.1126/science.268.5207.59.

Wallace, C. J., and T. J. Osborn, 2002: Recent and future modulation of the annual cycle. Climate Res., 22,1-11, doi:10.3354/ cr022001.

Wang, X. L., and V. R. Swail, 2001: Changes of extreme wave heights in Northern Hemisphere oceans and related atmospheric circulation regimes. J. Climate, 14, 2204-2221, doi:10.1175/1520-0442(2001)014<2204: COEWHI $>2.0 . \mathrm{CO} ; 2$.

Wild, M., 2009: Global dimming and brightening: A review. J. Geophys. Res., 114, D00D16, doi:10.1029/2008JD011470.

Wood, S. N., 2006: Generalized Additive Models: An Introduction with $R$. Chapman and Hall/CRC, $416 \mathrm{pp}$.

$\mathrm{Wu}, \mathrm{Z}$., and N. E. Huang, 2009: Ensemble empirical mode decomposition: A noise-assisted data analysis method. Adv. Adapt. Data Anal., 1, 1-41, doi:10.1142/S1793536909000047.

— E. K. Schneider, B. P. Kirtman, E. S. Sarachik, N. E. Huang, and C. J. Tucker, 2008: The modulated annual cycle: An alternative reference frame for climate anomalies. Climate Dyn., 31, 823-841, doi:10.1007/s00382-008-0437-z.

Zhang, X., L. A. Vincent, W. D. Hogg, and A. Niitsoo, 2000: Temperature and precipitation trends in Canada during the 20th century. Atmos.-Ocean, 38, 395-429, doi:10.1080/ 07055900.2000 .9649654 . 